\title{
How are decisions on care services for people with dementia made and experienced? A systematic review and qualitative synthesis of recent empirical findings
}

\author{
Annika Taghizadeh Larsson and Johannes H. Österholm
}

\section{Linköping University Post Print}

\section{Tweet}

N.B.: When citing this work, cite the original article.

Original Publication:

Annika Taghizadeh Larsson and Johannes H. Österholm, How are decisions on care services for people with dementia made and experienced? A systematic review and qualitative synthesis of recent empirical findings, 2014, International psychogeriatrics, (26), 11, 1849-1862.

http://dx.doi.org/10.1017/S104161021400132X

Copyright: Cambridge University Press (CUP): STM Journals http://www.cambridge.org/uk/

Postprint available at: Linköping University Electronic Press http://urn.kb.se/resolve?urn=urn:nbn:se:liu:diva-110917 


\title{
How are decisions on care services for people with dementia made and experienced? A systematic review and qualitative synthesis of recent empirical findings
}

\author{
Annika Taghizadeh Larsson, PhD (Corresponding author), \\ National Institute for the Study of Ageing and Later Life [NISAL] and Center for Dementia \\ Research [CEDER], \\ Department of Social and Welfare Studies, \\ Linköping University, \\ 60174 Norrköping, \\ Sweden \\ e-mail: annika.t.larsson@ liu.se \\ phone: +46 (0)11-363407
}

Johannes H. Österholm, reg OT,

Division of Health and Society and Center for Dementia Research [CEDER],

Department of Medical and Health Sciences,

Linköping University,

58183 Linköping,

Sweden

e-mail: johannes.h.osterholm@liu.se

phone: + $46(0) 13-282894$

1. The authors have not entered into an agreement with the funding organization that has limited their ability to complete the research as planned and publish the results.

2. The authors have had full control of all the primary data.

3. The authors are willing to allow the journal to review their data if requested. 


\section{ABSTRACT}

Background: During recent decades, there has been a growing recognition that people cannot be assumed incapable of making decisions about their own care solely on the basis of a dementia diagnosis and international agreements and legislative changes have strengthened the formal right for people with dementia to participate in decisions on care services. This raises important questions about how these decisions are currently made and experienced in practice. In this review, we address this question and highlight directions for further research. Methods: We searched CINAHL, PsycINFO, ASSIA, Social Services Abstracts, Science Direct, Academic Search Premier and PubMed. Twenty-four pertinent articles were identified, all representing qualitative studies. Relevant findings were extracted and synthesized along dimensions of involvement of the person with dementia in decisions on care services, using an integrative approach to qualitative synthesis.

Results: We identified three overarching ways in which people with dementia are involved, primarily, in the informal part of a process of decisions: excluded, prior preferences taken into account, and current preferences respected. Several (10) articles seemed to be based on the assumption that decisions on care services are invariably and solely made within the family and without participation of the person with dementia.

Conclusions: The review emphasizes the need for more updated research about international debates and agreements concerning capabilities and rights of people with dementia and about the (potential) formal contexts of care decisions in the country concerned. This, we argue, is vital for future knowledge production in the area.

Key words: dementia, aged care, Alzheimer's disease (AD), carers, nursing homes

Running title: Care decisions and people with dementia: a review 


\section{Introduction}

Decisions on care services such as day care, home care, and residential care, involve and affect many people with dementia and their families all over the world (Knapp et al., 2007; Schneider et al., 2002). During recent decades, there has been a growing recognition that people cannot be assumed incapable of making such decisions solely on the basis of a dementia diagnosis (Goldsmith, 1996; Kitwood, 1997; Wilkinson, 2001; Bartlett and O'Connor, 2010). Additionally, legislative changes have been made that strengthen the right for people with dementia to participate in decisions about care services (Tyrrell, Genin and Myslinski, 2006; Smebye, Kirkevold and Engedal, 2012).

For example, the Mental Capacity Act 2005, which came into force 2007 in England and Wales, seeks to empower people as long as they maintain capacity and protect them when they lack capacity to make a certain decision (Boyle, 2008). According to the act, "a person's capacity must be assessed specifically in terms of their capacity to make a particular decision at the time it needs to be made" (Department for Constitutional Affairs, 2007: 40). This stands in contrast to how people, prior to the act, were often judged as lacking decision-making capacity simply because of the presence of a certain diagnosis, such as dementia (Boyle, 2008).

Sweden has strengthened formal rights of people with dementia in recent decades, also illustrating that these changes may take different forms. In Sweden, existing forms of proxies do not have the right to intrude on any adult citizen's right to self-determination about whether she or he should receive care services such as residential care (Klemme Nielsen, 2012). Thus, in contrast to the situation in England and Wales, the challenges in allowing the person with cognitive disability the greatest possible freedom concerning decisions on care 
services - while at the same time preventing harm to the individual or others (Wilkinson, 2001) - are not acknowledged in Swedish legislation. Instead, they are transmitted to practice in full (Klemme Nielsen, 2012).

Reforms that clarify the rights of people with dementia to take part in care decisions have also been undertaken on the international level. According to The United Nations Convention on the Rights of People with Disabilities (CRPD), adopted by the United Nations in 2006, "persons with disabilities enjoy legal capacity on an equal basis with others in all aspects of life". The convention also states that all "parties shall take appropriate measures to provide access by persons with disabilities to the support they may require in exercising their legal capacity" (Article 12). As people with dementia, by the definition used in CRDP, are people with disabilities, the rights in the convention are applicable to them (Smith and Sullivan, 2012).

These changes on a discursive and formal level concerning capabilities and rights for people with dementia to participate in decisions on their own care raise questions about the related decision-making practices, and indicate the importance of summarizing current knowledge in this area. Formal and discursive changes might not easily transfer into action, and given the challenges embedded in enhancing the rights of people with dementia to participate in decisions about their own care, an important question is thus whether these changes may be traced in how decisions are currently made and experienced.

Thus, summarized knowledge is needed on how decisions on care services for people with dementia are currently made and experienced in different parts of the world, and within varying forms of legislative frameworks. Such knowledge may provide an important basis for 
future legislative and organizational developments in the area of care decisions and dementia. Knowledge of how decisions on care services for people with dementia are made and experienced by the parties concerned is also vital in order to provide relevant support to people with dementia and their families. These decisions are considered to be "a milestone both in the progress of the dementia and in the relationship between the person, the family and the professionals involved" (McDonald, 2010: p. 1233).

\begin{abstract}
Aim
The aim of this review and synthesis was to advance understandings of how decisions on care services for people with dementia are currently made and experienced by those involved. A particular focus was placed on the ways in which people with dementia are involved in these decisions.
\end{abstract}

Thus, the research questions were:

- In what ways are people with dementia currently involved in decisions on care services (such as home care, day care, and residential care)?

- What are the meanings and consequences of these ways of involvement, for people with dementia as well as for other parties potentially taking part in the process (e.g. family members, professionals)?

\title{
Methods
}

\section{Search strategy}

A systematic review (see Finfgeld, 2003; Saini and Shlonski, 2012) was conducted. We searched CINAHL, PsycINFO, ASSIA, Social Services Abstracts, Science Direct, Academic Search Premier using the terms "dement*" or "Alzheimer*" and "deci*" "autonomy", "self determ*", "self-determ*" (titles and abstracts; all possible combinations). Additionally, we searched PubMed using the MeSh terms "dementia" and "Alzheimer Disease" and "personal autonomy" or "decision making". 


\section{Study inclusion}

For inclusion in the review, a publication had to meet the general criteria of being published between 2005 and 2013 in a peer-reviewed journal, and be written in English. A starting point of 2005 was deemed appropriate, as the purpose of this review was to cover contemporary ways of making decisions about care services.

Studies also had to meet more specific criteria; they had to:

- be empirical studies

- deal with decisions on care services for people with dementia

Studies excluded were those dealing exclusively with:

- capacity assessments

- caregivers' or family members' motives and reasons for placing a relative with dementia in residential care, medical care or treatment, or

- people with learning disabilities who had acquired dementia.

The screening process (see Figure 1) resulted in 24 pertinent studies, all qualitative (see Table 1 for included studies). The last step of identifying these studies was full-text screening of 96 articles. As part of this process, uncertainties about the appropriateness of 28 of the 96 articles were solved by discussion and re-reading of the articles. Of these 28 articles, both authors agreed to exclude 20 articles. These excluded 20 publications were about medical decisions (e.g. Chrisp, Tabberer and Thomas, 2013), surrogate decision makers' beliefs and values, (e.g. Lopez and Guarino, 2011), transitions from one care residence to another (e.g. Horttana et al., 2011), health care practitioners' attitudes about advocacy services (e.g. Luke et al., 2008), factors or reasons for institutionalizing a person with dementia (e.g. Cairns, 2012), or training programs or preparation for future care for family caregivers (e.g. Mak and Sorensen, 2012). 
The complete list of studies excluded following a full text reading may be obtained from the authors.

//Figure 1 in here//

\section{Synthesis}

The 24 included studies were analyzed in accordance with an integrative approach to qualitative synthesis, which means that findings from qualitative studies are summarized in order to develop conceptual descriptions of phenomena across studies (Saini and Shlonski, 2012). We read the publications several times and extracted all findings (interview quotes and empirical descriptions) relevant to our research questions. These data were then coded, grouped, and compared, looking for congruencies and similarities in an iterative process. As a result, three themes were generated that covered all forms of involvement of people with dementia in decisions on care services represented in the extracted data: (a) excluded, (b) prior preferences taken into account and, (c) current preferences respected. The presence of each way of involvement among the findings of each individual study was systematically checked and noted. So were meanings and consequences for those concerned in each way of involvement, as well as other dimensions in the articles that we considered relevant or striking. Examples of such dimensions are information about the formal context and underlying assumptions about how these decisions are normally made, and by whom.

In the next sections, we will first communicate some general observations concerning the content and focus of the included articles. After that, we will describe sequentially the three overarching ways of involvement of people with dementia in decisions on care services that our analysis generated. 


\section{The included studies}

While the object of the review encompassed decisions on various types of care services, the majority (17) of the included 24 studies dealt exclusively with decisions on relocation to some form of residential care. Three articles explicitly focused on the perspectives of people with dementia (Aminzadeh et al., 2009; Fetherstonhaugh, Tarzia and Nay, 2013; Tyrell et al., 2006), and four (Forbes et al., 2012; Jaffe and Wellin, 2008; Smebye et al., 2012; St Amant et al., 2012) aimed at capturing the perspectives of several parties, including people with dementia. One article (McDonald, 2010) focused on the roles and performance of social workers. The remaining 16 articles aimed at capturing the perspectives of caregivers or family members.

//Table 1 in here//

The 24 studies were conducted in nine different countries. A striking observation made while going through the publications was that only four (Livingston et al., 2010; McDonald, 2010; St-Amant et al., 2012; Tyrrell et al., 2006) described the legal framework in the country concerned. Another two studies (Smebye et al., 2012; Wolfs et al., 2012) encompassed general contextual statements such as "The Western ideal of autonomy in health matters has led to many countries passing laws giving patients the right to participate in deciding about their treatment and care" (Smebye et al., 2012: 242). The rest (18 studies) demonstrated a complete lack of legal context, or seemed to be based on the assumption that this aspect was known to the reader and/or also applied in other parts of the world. An implicit point of departure in several (10) of these studies seemed to be that people with dementia are, invariably, placed in residential care by family members. This is despite the fact that placing 
people with dementia in residential care is in some countries a legally regulated option only under certain circumstances (for example if the person is considered to be at risk) (Livingston et al., 2010; McDonald, 2010; St-Amant et al., 2012). In other countries (e.g. Sweden), no such options exist (Klemme Nielsen, 2012; see also Tyrell et al., 2006). The apparent lack of legal context in most of the articles might be related to a pure focus on the informal decision making done within a family. Thus, in most of the studies decisions on care services were dealt with solely as a family matter, without involvement of professional "gate keepers" and without formal regulations. Whether such phenomena actually exist in the country in question remains unknown. As illustrated in other included studies (e.g. McDonald, 2010), these informal decisions may only be one part of a process of decisions that is partly carried out within a formal and organizational context, in which professionals such as social workers are important parties.

Three of the studies (Chang and Schneider, 2010; Chang et al., 2011; Kwon and Tae, 2012), all conducted in Eastern Asia (Taiwan and Korea) do not acknowledge any (potential) legal and organizational context, but place the study within the context of conflicting cultural ideals. Caring for an older relative at home, according to these publications, is considered normal and proper within traditional ideals of filial piety. However, due to major changes and new ideals in modern society, an increasing number of people with dementia are placed in residential care by their families. Because of clashing cultural ideals, according to the publications in question, these family members might experience the process of placing an older relative in residential care "...quite differently than the caregivers from other cultural backgrounds" (Kwon and Tae, 2012: 144). 


\section{Ways of involvement}

Having reported some general observations and findings concerning the content and focus of the included articles, we will now present our synthesis of findings on the involvement of people with dementia in decisions on care services. We will present sequentially the three identified ways that people with dementia were involved in decisions on relocation to residential care. These themes are: (a) excluded, (b) prior preferences taken into account and, (c) current preferences respected. Meanings and consequences will also be described for each way of involvement for the parties concerned (the person with dementia, family members/caregivers, professionals) as identified during the analysis.

\section{Excluded}

The most frequently illustrated way that people with dementia were involved in decisions on their future care, was that they were excluded from these decisions. This form of (non-) involvement appeared more or less explicitly in all but one of the articles. The exception is Adams' (2006) study, which also stands out by focusing on (caregivers of) people in the early stages of dementia.

In the 23 studies examined, two levels of exclusion were identified. The first level meant that the person with dementia was not told about the decision before implementation. Thus, the person with dementia was given no chance to voice her /his own viewpoints on the matter. This level was identified in five studies (Chene, 2006; Ducharme et al., 2012; Smebye et al., 2012; Aminzadeh et al,, 2009; St-Amant et al., 2012). In four of these studies, family members were presented as the decision makers. In one study, (St-Amant et al., 2012), it was a case of formally appointed surrogate decision makers who refrained from acknowledging the wishes of the individuals with dementia as expressed earlier in the illness trajectory. They refrained even though this, according to the study in question, meant violation of a legally stipulated procedure. The studies also reveal that this level of (complete) exclusion of people 
with dementia occurred despite, or even because of, family members knowing that the decision was against the older relative's will (see Ducharme, Couture and Lamontagne, 2012).

The second level of exclusion was identified in three studies (Livingston et al, 2010; Chang et al., 2011; Chene, 2006). This level implies that the involved individuals with dementia were told about the decision made by someone else before implementation, and thus given a chance to present their viewpoints. However, the decision was carried through even though the person with dementia explicitly objected. Four studies (Golden, 2010; Elliott et al., 2009; Weber and Bailey, 2005; Forbes et al., 2012; Aminzadeh et al., 2009) present examples of how people with dementia are deceived into entering residential care and day care by being told that they are moving, or going somewhere else. Participating caregivers in Weber's and Bailey's (2005) focus groups refer to this phenomena as "therapeutic fibbing", which includes "...telling the patient that the move was temporary, stating that the patient was going to a resort or school, or telling the individual being placed that they were going there for medical tests or other health-related activities" (p. 28). Other strategies, presented in four studies (Livingston et al., 2010; Wolfs et al., 2012; Jaffe and Wellin, 2008; Keady et al., 2007), were to introduce services a little at a time or in various ways persuade the individual to accept relocation to residential care or home care. The latter include enlisting the doctor's medical authority. On the one hand, these strategies seem slightly more inclusive than deliberately deceiving the person with dementia, but on the other hand they also seem more timeconsuming and may, according to Jaffe and Wellin (2008), encompass almost a year of "bargaining and negotiation" (p.131).

\section{Meanings and consequences for the parties involved}

What then are the meanings and consequences for the parties involved in decisions on care services that are made without consent, or against the explicit will of the person with 
dementia? As the majority of the studies included in our review focused exclusively on the perspective of family caregivers, they provide a rich basis for answering the question from this perspective. The coherent picture provided is that deciding on relocation to residential care, without consent of the person with dementia in question, may cause considerable difficulties for family caregivers such as feelings of failure, betrayal, and guilt. On the other hand, family caregivers participating in these studies also “...recognized that it was the only way to ensure their family member's safety and wellbeing" (Forbes et al., 2012, p.8; see also Garity, 2006). They also “...mentioned that their guilt over placement was decreased by knowing that their family member needed 24-hour care" (Garity, 2006, p.45). These studies also reveal that other family members or professionals, by supporting the decision, may alleviate guilt by "giving permission”. They may also help to re-conceptualize “...care homes as providing safety, either for the caregiver or the person with dementia, particularly if homecare services were refused" (Livingston et al., 2010, p.5) by the person with dementia. Furthermore, in one study, exclusion of a person with dementia by not informing her or him about the decision is presented as potentially beneficial as it "... allowed the caregiver to attenuate his/her own negative feelings about placement and to avoid emotional reactions on the part of the person with dementia" (Ducharme et al., 2012, p. 207). To inform the person with dementia about the decision on relocation, in cases when this was the route chosen, stands out as a difficult and painful experience for caregivers (e.g. Chang et al., 2011).

The studies do not provide much insight into the meanings and consequences for an individual with dementia of having to accept care services without consent or against one's will. One exception is the study by Aminzadeh et al. (2009), which set out to explore the perspectives of persons with dementia on relocation to a residential care facility. Summing up, Aminzadeh et al. (2009) state that perceiving the process as dominated by caregivers, for the people with dementia, resulted “...in a perception of further loss of agency, autonomy, choice, 
and control, which may have, in turn, contributed to the uncertainties and the overall more negative responses of these individuals to relocation" (p. 491). Similarly, Fetherstonhaugh et al. (2013) conclude: "Being ignored made the participants feel insignificant, as though their identity as a person was under threat, and that they were nothing more than a 'piece of wood' (Participant 5) who should 'just go home and disappear' (Participant 4)” (p. 148).

\section{Prior preferences taken into account}

Another overarching way that people with dementia were involved in decisions on their future care touched upon in two of the included publications (Elliott et al., 2009; Forbes et al., 2012), was that their prior preferences were taken into account.

One manner of considering prior preferences that was identified in these two studies implies that the fact that the person with dementia in early stages of the trajectory or "...prior to the onset of dependency" (Elliot, 2009, p. 254) had delegated her/his decision-making authority to a surrogate decision maker was respected (see also Forbes et al., 2012). Thus, it was this person, previously chosen or accepted by the person with dementia to decide on her/his behalf in the future, who made the decision on care services or relocation. Another identified way in which previous preferences were taken into account was that specific wishes of the person with dementia as known by family members “...were incorporated in the decision, using statements that had been communicated before the elder's loss of capacity. Sometimes this was based in Advance Directive planning; other times, important conversations offered guidelines" (Elliot, 2009, p. 255).

\section{Meanings and consequences for the parties involved}

None of the studies tell us anything about the meanings and consequences of delegating one's decision-making authority to another person, or making a decision on relocation or care services based on preferences that one has expressed before or earlier in the trajectory of dementia. However, Elliot's study (2009) shows that delegation of decision-making authority 
may be positive for the person who is asked to fill the role as a surrogate decision maker. As expressed by a participant in the study: "It's an honour to be chosen to do that role, you know, cause it means he thinks enough of me to trust me to do it" (p. 254). Furthermore, Forbes et al. (2012) shows that care partners/family caregivers and health care professionals preferred this way of dealing with the transfer of decision-making authority to another person before waiting until the person with dementia has been declared incompetent of making decisions. That is, they preferred that this transfer "... was completed while the PWD (person with dementia, author's comment) could still participate in this process" (Forbes, 2012, p.7).

On the other hand, as illustrated in St-Amant et al.'s (2012) study, despite surrogate decision makers being formally obliged to consult (other) family members, this is not always done in practice. It makes those (other) family members feel removed and excluded from the decision-making process, once their relative has been declared incompetent. Concerning meanings and consequences of incorporating specific wishes of the person with dementia that had been communicated earlier in the illness trajectory in the decision, this might also, according to Elliot et al.'s study (2009), cause certain problems in the family as not everyone necessarily agrees on this being the 'right' way.

\section{Current preferences respected}

The third identified way of involvement of people with dementia in decisions on care services was that their current preferences were respected. This way of involvement was recognized in altogether eight articles (Adams, 2006; Caron et al., 2006; Ducharme et al., 2012; McDonald, 2010; Smebye et al., 2012; Tyrrell et al., 2006; Wolfs et al., 2012; Elliot, 2009). These studies provide illustrations of decisions made in agreement by family caregivers and people with dementia, such as people with dementia being “ ... 'open’ to the idea of being placed, having realized that his/her living environment was no longer adequate" (e.g. Ducharme et al., 2012). 
Concerning people in the very early stages of dementia (Elliot et al., 2009) there are also examples of decisions “...made closely involving the elder's autonomous wishes” p. 256). Furthermore, several examples are provided of family caregivers and professionals who chose to respect the current wishes of the person with dementia not to accept care services, even if they themselves had a diverging opinion.

We also identified examples of professionals basing their (formal) decisions about care services on the wishes of the person with dementia, in cases when this meant acting against the explicit preferences of family caregivers. McDonald's (2010) study in the U.K. shows that the social worker's decisions sometimes respected the will of the person with dementia, even though it did not match the will and expectations of the family caregiver or other (selfappointed) representative who had contacted the social worker. The social workers justified these decisions by using the Mental Capacity Act 2005 and the legal test of capacity to argue for the rights of the people concerned. According to McDonald's study, it was not unusual that family members sought to block these assessments by arguing that the diagnosis of dementia as such was evidence of lack of capacity to make the decision. Caron et al.'s (2006) study provides examples of doctors making decisions corresponding to the will of people with dementia, but diverging from the wishes expressed by family caregivers. One such example presented concerns a man with dementia who was allowed by a doctor to return home from a short-term geriatric unit, despite the fact that the family caregivers had told the same doctor that they strongly believed that the best solution for the care of their older relative would be residential care.

\section{Meanings and consequences for the parties involved}

The studies in question provide only a few examples of meanings or consequences for the parties involved of respecting the present preferences of the persons with dementia. 
According to the study carried out by Caron et al. (2006), a family caregiver, experiencing that one's evaluations of the care situation are disregarded by health care professionals while the preferences of the person with dementia are acknowledged, may result in frustration with the situation. Frustration may also be the result of a family caregiver taking the preferences of the person with dementia into account, while at the same time perceiving that the person with dementia overestimates her/his own ability and does not see the need to move to an environment that offers more services. Similarly, Ducharme et al. (2012) found that a consequence of including the person with dementia in the decision by acknowledging her/his reluctance towards relocation, was that the family caregiver kept the person at home, while at the same time recognizing placement as the best option under the circumstances.

\section{Discussion}

In the sections above, we have illustrated three overarching ways in which people with dementia are involved in decisions on care services or relocation to residential care, as identified in recent empirical research. These are: excluded, prior preferences taken into account, and current preferences respected. We have also described identified meanings and consequences of each way of involvement for the parties concerned. Because of the scope of the included studies, the synthesis presented deals primarily with the involvement of people with dementia in the informal part of the decision-making, carried out within a family.

What then does our study tell us about how decisions on care services are currently made and experienced in practice, and about the involvement of people with dementia in these decisions?

First, as the publications analyzed included few empirically grounded examples of people with dementia having more than a minimal say in decisions about their future care, they tell 
more about the exclusion of people with dementia from care decisions than about their active involvement. The family caregivers' experiences of excluding the person with dementia from these decisions are most often characterized by feelings of guilt and betrayal. Challenging assumptions in the studies conducted in East Asia, these feelings seem to be shared by caregivers in countries all over the world. They may, however, be alleviated by professionals confirming that the decision made is the right one, as well as by recognizing that the decision, although not appreciated by the person with dementia, is in her/his best interests. Taking the perspective of people with dementia, feelings of marginalization seem to characterize exclusion from the decisions in question. Such sentiments also seem to characterize the experiences of some family caregivers whose wishes and preferences are not acknowledged, in cases when a surrogate decision maker is formally appointed at the time of "lost capacity". On the other hand, the person appointed appreciates being trusted. Concerning taking the current preferences of the persons with dementia into account, the included studies only provide examples of negative consequences for family caregivers in terms of feelings of frustration. Thus, this review does not really provide any answers on how to include the preferences of the person with dementia, without this being at the expense of the wellbeing of caregivers. Nor does it provide knowledge on what it might mean to people with dementia that their preferences are respected.

Instead, the informal decision-making concerning care services for people with dementia emerges as complex, with no clear "winners", but many "losers". If the results of the few studies including the organizational context of these decisions are added, an even more complex decision-making process emerges. Additionally, as illustrated by these latter studies, the formal decision makers' decisions do not necessarily correspond to the informal decisions 
made by family members. Thus, despite being both complex and protracted, informal decisions may not necessarily, and not everywhere, end up in implementation of care services.

Notably, none of the studies actually provide examples of people with dementia initiating the decision-making process by expressing a need or wish for services or relocation. Instead, the studies almost exclusively illustrate whether - and how - people with dementia were given an opportunity to react on decisions made by others, as well as on the potential impact of these reactions. However, this might not mirror what is actually going on in the world outside the publications in question. Instead, the few illustrations of active participation of people with dementia might be related to the dominant focus on family caregivers' perspectives in the articles. Furthermore, a surprising amount of the studies included seem to be based on a taken-for-granted assumption that these decisions are normally made without participation of the individual with dementia, and without taking her/his opinions and remaining abilities into account. Thus, this review confirms that dementia is still largely perceived and investigated as a burden of care for caregivers. It also suggests that the preconditions for, and meanings of, being an agent with dementia who is able to do things for her/himself and invoke rights as a member of a community - are still under-researched and under-theorized (Bartlett and O’Connor, 2010). Thus, while there might be a growing recognition that people cannot be assumed incapable of making decisions about their own care solely on the basis of a dementia diagnosis (see e.g. Kitwood, 1997; Wilkinson, 2001; Bartlett and O’Connor, 2010) and their formal rights to participate in the decisions have been strengthened during recent decades (see e.g. Boyle, 2008; Smith and Sullivan, 2012, our work suggests that these changes have not had a major impact on research in the area. 


\section{Conclusions}

A conclusion that can be drawn from our review is that recent research on care decisions for people with dementia does not provide a complete picture of how these decisions are currently made in practice. Specifically, the involvement of people with dementia in these decisions does not seem to be sufficiently and adequately addressed.

Hence, this review raises important implications for future research in the area of decisions on care services for people with dementia. It emphasizes the need for updated studies and publications directed to an international audience on formal and discursive changes concerning capabilities and rights of people with dementia. One example of such a change is the clarification of the legal status of people with disabilities - and people with dementia (Smith and Sullivan, 2012) - in CRPD in 2006. Another example is that scholars have stated for years now that persons with dementia have the ability to voice their feelings and preferences, even in late stages of the disease (see Goldsmith, 1996; Kitwood, 1997).

Thus, we would like to argue that people with dementia being placed in residential care by family caregivers is outdated, as an uncriticized or taken-for-granted point of departure in a research project, even though this might be what is actually going on "out there". Such takenfor-granted assumptions appear as particularly striking in the context of other dementia scholars (in some cases in the same country) currently arguing that "... it is not enough to simply include people in decisions about their care; we must also convey to the person that their inclusion matters.” (Bartlett and O'Connor, 2010, p. 43).

We would also like to suggest that even if a study aims at capturing the perspectives of caregivers, as a scholar, knowing and informing the reader about the (potential) legal and organizational context of the decisions in question is vital for future knowledge production in the area. Additionally, as the studies identified have similar designs that are based mainly on 
qualitative interviews, research on decisions on care services for people with dementia would probably benefit from the complementary use of other methods and empirical materials.

\section{Conflict of Interest}

None.

\section{Description of authors' roles:}

Both authors cooperated in the formulation of research questions, designing the review and conducting the identification of relevant studies. A. Taghizadeh Larsson was responsible for the analysis and for writing the paper. J. H. Österholm was responsible for conducting the literature search, assisting with the analysis and writing and producing tables and figures.

\section{Acknowledgments}

We are grateful to Anna Pettersson, librarian at Linköping University, for her support in the literature search phase. The research reported in this study was funded by a generous grant from the Swedish Riksbankens Jubileumsfond (M10-0187:1).

\section{References}

Adams, K. B. (2006). The transition to caregiving: The experience of family members embarking on the dementia caregiving career. Journal of Gerontological Social Work, 47, 329.

Aminzadeh, F., Dalziel, W. B., Molnar, F. J. and Garcia, L. J. (2009). Symbolic meaning of relocation to a residential care facility for persons with dementia. Aging \& Mental Health, 13, 487-496. doi: 10.1080/13607860802607314. 
Bartlett, R. and O'Connor, D. (2010). Broadening the Dementia Debate: Toward Social Citizenship. Bristol: Policy Press.

Boyle, G. (2008). The Mental Capacity Act 2005: Promoting the citizenship of people with dementia? Health and Social Care in The Community, 16, 529-537.

Cairns, M. (2012). In sickness and in health: An exploration of some of the unconscious processes involved in the decision by family caregivers to place a family member with dementia in residential care. Psychoanalytic Psychotherapy, 26, 34-47. doi:

$10.1080 / 02668734.2011 .652976$.

Caron, C., Ducharme, F. and Griffith, J. (2006). Deciding on institutionalization for a relative with dementia: the most difficult decision for caregivers. Canadian Journal on Aging, 25, 193-206.

Chang, Y. and Schneider, J. (2010). Decision-making process of nursing home placement among Chinese family caregivers. Perspectives in Psychiatric Care, 46, 108-118. doi:10.1111/j.1744-6163.2010.00246.

Chang, Y., Schneider, J. and Sessanna, L. (2011). Decisional conflict among Chinese family caregivers regarding nursing home placement of older adults with dementia. Journal of Aging Studies, 25, 436-444.

Chene, B. (2006). Dementia and residential placement: a view from the carers' perspective. Qualitative Social Work, 5, 187-215.

Chrisp, T., Tabberer, S. and Thomas, B. (2013). Bounded autonomy in deciding to seek medical help: Carer role, the sick role and the case of dementia. Journal of Health Psychology, 18, 272-281. doi: 10.1177/1359105312437265 
Department for Constitutional Affairs ( 2007). Mental Capacity Act 2005: Code of Practice. London: The Stationery Office.

Ducharme, F., Couture, M. and Lamontagne, J. (2012). Decision-making process of family caregivers regarding placement of a cognitively impaired elderly relative. Home Health Care Services Quarterly, 31, 197-218. doi:10.1080/01621424.2012.681572.

Dwyer, S. (2005). Older people and permanent care: Whose decision? British Journal of Social Work, 35, 1081-1092.

Elliott, B., Gessert, C. and Peden-McAlpine, C. (2009). Family decision-making in advanced dementia: narrative and ethics. Scandinavian Journal of Caring Sciences, 23, 251258. doi:10.1111/j.1471-6712.2008.00613.

Fetherstonhaugh, D., Tarzia, L. and Nay, R. (2013). Being central to decision making means I am still here! The essence of decision making for people with dementia. Journal of Aging Studies, 27, 143-150.

Finfgeld, D.L. (2003). Metasynthesis: The state of the art - So far. Qualitative Health Research, 13, 893-904. doi:10.1177/1049732303253462.

Forbes, D. A., et al. (2012). Knowledge exchange throughout the dementia care journey by Canadian rural community-based health care practitioners, persons with dementia, and their care partners: an interpretive descriptive study. Rural \& Remote Health, 12, 1-15.

Garity J. (2006). Caring for a family member with Alzheimer's disease: coping with caregiver burden post-nursing home placement. Journal of Gerontological Nursing, 32, 3948. 
Givens, J., Lopez, R., Mazor, K. and Mitchell, S. (2012). Sources of stress for family members of nursing home residents with advanced dementia. Alzheimer Disease \& Associated Disorders, 26, 254-259.

Golden, M.A. (2010). Dialectical contradictions experienced when placing a spouse with dementia in a residential care facility. Qualitative Research Reports in Communication, 11, 14-20.

Herissone-Kelly, P.P. (2010). Capacity and consent in England and Wales: The Mental Capacity Act under scrutiny. Cambridge Quarterly of Healthcare Ethics, 19, 344-352. doi:10.1017/S0963180110000125.

Jaffe, D. and Wellin, C. (2008). June's troubled transition: adjustment to residential care for older adults with dementia. Care Management Journals, 9, 128-137.

Keady, J., Ashcroft-Simpson, S., Halligan, K. and Williams, S. (2007). Admiral nursing and the family care of a parent with dementia: using autobiographical narrative as grounding for negotiated clinical practice and decision-making. Scandinavian Journal of Caring Sciences, 21, 345-353.

Kitwood, T. (1997). Dementia Reconsidered - The Person Comes First. Buckingham: Open University Press.

Klemme Nielsen, M. (2012). Laglöst land [A lawless area]. In L. Broström and M. Johansson (Eds) Ställföreträdarskap i Vård och Omsorg [Deputyship in health and social care] (pp. 3777). Malmö: Gleerups.

Knapp M., et al. (2007). Dementia UK: A Report into the Prevalence and Cost of Dementia. [WWW document]. URL http://www.alzheimers.org.uk/News_and_Campaigns/Campaigning/PDF/ 
Kwon, S-H. and Tae, Y-S. (2012). Nursing home placement: The process of decision making and adaptation among adult children caregivers of demented parents in Korea. Asian Nursing Research, 6, 143-151.

Livingston, G., et al. (2010). Making decisions for people with dementia who lack capacity: qualitative study of family carers in UK. British Medical Journal, 341. doi: http://dx.doi.org/10.1136/bmj.c4184.

Lopez, R. P. and Guarino, A. J. (2011). Uncertainty and decision making for residents with dementia. Clinical Nursing Research, 20), 228-240. doi: 10.1177/1054773811405521.

McDonald, A. A. (2010). The impact of the 2005 Mental Capacity Act on social workers' decision making and approaches to the assessment of risk. British Journal of Social Work, 40, 1229-1246. doi:10.1093/bjsw/bcq021.

Luke, L., Redley, M., Clare, I. and Holland, A. (2008). Hospital clinicians' attitudes towards a statutory advocacy service for patients lacking mental capacity: implications for implementation. Journal of Health Services Research \& Policy, 13, 73-78. doi: 10.1258/jhsrp.2007.007084.

Mak, W. and Sörensen, S. (2012). Trajectories of preparation for future care among firstdegree relatives of Alzheimer's disease patients: An ancillary study of ADAPT. Gerontologist, 52, 531-540.

Saini, M. and Shlonsky, A. (2012). Systematic Synthesis of Qualitative Research. New York: Oxford University Press.

Schneider, J. et al. (2002). Formal and informal care for people with dementia: factors associated with service receipt. Aging and Mental Health, 6, 255-265. 
SFS 1949:381. Föräldrabalk [Act on the Children and Parents Code]. Stockholm:

Justitiedepartementet.

Sherwin, S. and Winsby, M. (2011). A relational perspective on autonomy for older adults residing in nursing homes. Health Expectations, 14, 182-190.

Smebye, K., Kirkevold, M. and Engedal, K. (2012). How do persons with dementia participate in decision making related to health and daily care? A multi-case study. $B M C$ Health Services Research, 12, 241. doi:10.1186/1472-6963-12-241.

Smith, A. and Sullivan, D. (2012). A new ball game: the United Conventions on the Rights of Persons with Disabilities and assumptions in care for people with dementia. Journal of Law and Medicine, 20, 28-34.

Sokolowski, M. (2010). Advance directives and the problem of informed consent. Journal of Ethics in Mental Health, 5, 1-6.

St-Amant, O., et al. (2012). Making care decisions in home-based dementia care: Why context matters. Canadian Journal on Aging, 31, 423-434. doi:10.1017/S0714980812000396

\section{Strang, V. R., Koop, P. M., Dupuis-Blanchard, S., Nordstrom, M. and Thompson, B.} (2006). Family caregivers and transition to long-term care. Clinical Nursing Research, 15, 2745. doi:10.1177/1054773805282356.

Tyrrell, J., Genin, N. and Myslinski, M. (2006). Freedom of choice and decision-making in health and social care: views of older patients with early-stage dementia and their carers. Dementia, 5, 479-502. 
Weber, J. and Bailey, K. (2005). Using focus groups to assess pre- and post-placement needs for caregivers of individuals with Alzheimer's disease. Journal of Social Work in Long-Term Care, 3, 21-36.

Wilkinson, H. (2001). Empowerment and decision-making for people with dementia: the use of legal interventions in Scotland. Aging \& Mental Health, 5, 322-328

Wolfs, C., et al. (2012). Rational decision-making about treatment and care in dementia: A contradiction in terms? Patient Education \& Counseling, 87, 43-48. 
Electronic databases searched. Potentially re levart studies idertif id inc huding deplic ates $(n=3611)$

Drplicates removed with the Erdkote software program $(n=1204)$

Potertially relevart studies after remowal of delicates with the Erdilote softorire program $(n=2407)$

Ineligble studies e xchuded after an ritialmarual title and abstract sace ening, as both authors agree d that they did notmeet the geners and specific ateria -for example, dealing with medic al de cisions, end-of-life care decisions, or autonomy and driving $(n=2311)$

Potertially appropriate studies, after title and abstract sceening, down-loade d or ordered for full text reading $(n=96)$

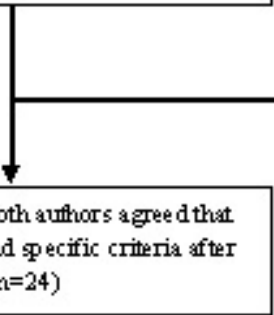

Stodies e xchuded, based on a full text reading, as both anthors agreed that they did not meet the general and spec ific criter is $(n=72)$

Soudies on which both auflors agree d that theymet general and specific criteria af ter a full textreading $(n=24)$ 
Table 1 Presentation of included studies

\begin{tabular}{ll}
\hline STUDY & PURPOSE \\
\hline Adams (2006) & $\begin{array}{l}\text { To gain an in-depth understanding of early or } \\
\text { prospective care givers' subjective experiences } \\
\text { with MCI or the early stages of dementia. }\end{array}$
\end{tabular}

Aminzadeh et To explore the perspectives of PWDs on the al. (2009) meanings and experiences associated with relocation to a residential care facility.

Caron,

Ducharme \& Griffith

(2006)

To explore the decision-making process used by family care givers for institutionalizing a family member with dementia and to develop a the oretical model, based on the caregivers' perspectives.

Chang \& Schneider (2010)

To understand the process and difficulties that Chinese family caregivers experience when making a nursing home placement decision for pWDs.

Chang, Schneider \& Sessanna (2011)

To describe factors influencing decisional conflicts among Chinese family caregivers regarding residential care placement of PWDs.

$\begin{array}{ll}\text { LOCATION } & \text { TYPE OF } \\ & \text { STUDY }\end{array}$

\section{SAMPLE}

Canada
Qualitative; phenomenolog

$y$, and

groundad

theory

Qualitative;

grounded

the ory

Canada

Qualitative; grounded

theory

Taiman

20 spouses or adult

daughters of

persons with mild

dementia or MCI.

16 PWDs

14 caregivers of 8

PWDs

Qualitative; grounded

theory

30 family

caregivers

Taiman

Qualitative

30 family

caregivers

\section{DATA COLLECTION}

Semi-structured interviews.

In-depth interviews 2 months prior to relocation.

In-depth interviews.

In-depth interviews.

In-depth interviews. 
quantitative

(Only the

qualitative

study of

relevance).

Ducharme,

Couture \&

Lamontagne

(2012)

\section{Elliott et al.}

(2009)

To develop a model of the family caregiver decision-making process re garding placement of a cognitively impaired elderly relative.

\section{Canada}

To describe and understand the ethical thinking surrogates on behalf of their cognitively impaired elders.

Fetherstonhav gh, Taria \&

To ithminate the essence of decision making for PWDs

Avstralia dementia care ifformation more effectively by examining their information needs, how these change over time, and how they access, assess, and apply the knowledge.

Garity (2006) To identify how family care givers coped with the burden of post-residential care placement of a

U.S. family member with $A D$.
Qualitative; grounded

18 caregivers of theory

Qualitative.

Qualitative; phenomenolog y

$6 \mathrm{PWD} 3$

39 family members of persons with severe dementia

Qualitative; interpretive descriptive

Semi-structured interviews conducted at 6 month intervals over an average 20 months.

Bight focus groups.

Two participants were interviewed in their homes and 4 participants were interviewed by telephone.

9 rural dementia care networks which included 5

PWDs, 14 care partners, $14 \mathrm{HCP} s$

Qualitative; 18 caregivers
80 interviews were conducted 3 separate times.

Semi-structured interviews. 
To describe dialectical contradic tions experienced in the context of a wife placing her husband with dementia in a care facility.
U.S.

Qualitative; case study and bodily decline are constructed in the context of the social and organizational relations of caregiving.

To capture an autobiographical account of a family carer's journey through the experience of her mother's dementia and the reflexive dialogue and shared care planning that ensved with the Admiral Nurse.

To explore and describe the process of residential care placement decision making and adaptation among adult children caregivers of parents with dementia in Korea and to generate a substantive the ory grounded on their experiences.
Qualitative; ethnography

U.S.

One PWD, her attomey, her confidant, staffmembers

U.K.

Korea

$\begin{array}{ll}\text { Qualitative; } & 16 \text { adult children } \\ \text { groundad } & \text { caregivers }\end{array}$

Qualitative; narrative and antobiographic

One family carer, 1 Admiral Nures at

theory
Data derived from a larger project (Golden \& Lund, 2009). Observations of twenty metings of a support group for spouses of pWDs. Twelve of these meetings contained remarks related to the spouse placing the PWD in residential care.

Observational and interview data spanning 3 years in the setting.

The family member's narrative was cap tured using practitioner research principles and 10 interview contacts; the autobiography was then used as the basis for therapeutic and clirical work, as reported and jo intly negotiated.

In-depth unstructured interviews with individual participants. 

of and barriers to such decisions, in order to produce information for family carers about overcoming barriers.

who had made

decision on behalf of PWDs

To explore the ways in which soc1al workers constucted their roles and performance in a new legal context, which linked issues of law and risk.

\section{Smebye et al.} (2012).

MeDonald $(2010)$
To gain a better understanding of how PWDs participated in maling decisions about health care and how their family carers and professional caregivers influenced decision making
St-Amant et al. (2012)
To examine the taken-for-granted cultural valves, beliefs, and practices embedded within dementia home care. What are the relationship experiences of PWDs, families, and providers engaged in dementia care? What factors influence the negotiation and which conditions support and strengthen the relationships between and among them? What changes are needed in health services policy and program delivery to enharre the quality of home-based dementia care?
U.K.

Qualitative; thematic

analysis, grounded

theory

Norway

Qualitative milti-case design; hermenevtical interpretive.

30 participants in to tat; $10 \mathrm{PWD}, 10$ family carers, 10 profe ssional caregivers.

Canada

Qualitative; critical ethnography

9 dementia care networks; 9 PWDs, 25 family caregivers, 10 formal $\mathrm{HCPs}, 7$ community case managers.
Document review, reading of files and semistruc tured interviews with social work staff.

Semi-structured interview with family carers and professional caregivers. Field notes from participant observation of inferactions between PWDs and professio nal care givers during moming care or activities at a day center.

In-depth, semi-structured interviews; 37 initial interviews and 15 follow-wp interviews. Of the 37 initial interviews, 7 were condvcted joindly with the PWD and their family member. 

at entry into the placement waiting list and at dementia in residential care and how they coped during this period of waiting and transition.

Tyrrell et al. To explore the conditions of decision making with PWDs, in order to understand to what de gree they are involved in making choices about their care arrangements.

France Qualitative

21 PWDs, 21 primary carers

U.S.

To gain knowledge from care givers who cho prepare themselves for the placement of a PWD in residential care, and to identify recommendations for care givers considering placement in residential care.

Wolfset al (2012)

To gain caregivers' insights into the decision-

The making process in dementia patients with regard to treatment and care. Netherlands
Qualitative, grounded theory
11 spouses and 12 children of PWDs
Semi-structured telephone interviews with informal caregiver of the PWD and focus group interviews.
Semi-structured interviews, conducted jointly with the PWDs and their care givers, so that the PWD could recall a situation where a decision regarding care had been made. Both PWD and carer were then interviewed separately about how this decision had been made.

Focus groups. 